\title{
BMJ Open Support for mobilising medical students to join the COVID-19 pandemic emergency healthcare workforce: a cross-sectional questionnaire survey
}

To cite: Astorp MS, Sørensen GVB, Rasmussen S, et al. Support for mobilising medical students to join the COVID-19 pandemic emergency healthcare workforce: a cross-sectional questionnaire survey. BMJ Open 2020;10:e039082. doi:10.1136/ bmjopen-2020-039082

- Prepublication history for this paper is available online. To view these files, please visit the journal online (http://dx.doi. org/10.1136/bmjopen-2020039082).

Received 03 April 2020 Revised 17 August 2020 Accepted 20 August 2020

D) Check for updates

(c) Author(s) (or their employer(s)) 2020. Re-use permitted under CC BY-NC. No commercial re-use. See rights and permissions. Published by BMJ.

${ }^{1}$ Department of Geriatric Medicine, Aalborg University Hospital, Aalborg, Denmark ${ }^{2}$ Department of Clinical Medicine, Aalborg Universitet, Aalborg, Denmark

${ }^{3}$ Orthopaedic Surgery Research Unit, Aalborg University Hospital, Aalborg, Denmark

${ }^{4}$ Faculty of Medicine, Aalborg University, Aalborg, Denmark

Correspondence to Dr Mike Sæderup Astorp; m.astorp@rn.dk

\section{ABSTRACT}

Objective To identify what motivates medical students to join a pandemic emergency healthcare workforce.

Design Cross-sectional study.

Setting Aalborg University, Denmark.

Participants All medical students.

Main outcome measures Motivational points as perceived by the students to be important. Demographic characteristics and 11 motivational domains scored on a Visual Analog Scale from 0 (low) to 100 (high) responding to the question: 'To what degree are the following statements important for you to join a national emergency preparedness workforce?' The questionnaire was developed by an expert panel in a process of four iterations.

Results A total of 486 students of 688 (70.6\%) completed the survey within 7 days in March 2020. 80\% had decided to join the pandemic emergency healthcare workforce. Ranked median scores for motivational statements in each domain were: care, 100; learn, 90; pride, 83; team, 77; needed, 75; safety, 75; supervision, 75; job, 73; duty, 66; salary, 62 ; historic, 50 . Supervision $(p<0.001)$, salary $(p<0.001)$ and duty $(p=0.001)$ were given increasing priority with advancing study years. Interestingly, students added that support by the university and clarification of study plans were priorities.

Conclusions Results guide decision-makers and colleagues on how to motivate or reinforce medical students in joining the pandemic emergency healthcare workforce. Importantly, students emphasised protection for themselves.

\section{INTRODUCTION}

In December 2019, a new virus emerged in Wuhan city, the capital of Hubei province in China, the SARS-CoV-2, previously known as 2019-nCoV. ${ }^{1}$ The virus spreads rapidly, and mortality is a concern as death counts are climbing worldwide. $^{2}$ On 11 March 2020, the Director-General of WHO declared the outbreak of SARS-CoV-2 a pandemic. ${ }^{2}$

Turning to Europe, the impact of SARS-CoV-2 is currently seen in Italy with
Strengths and limitations of this study

- A limitation was the focus on positive motivational points while omitting negative aspects.

- Student involvement in the construction of the questionnaire was hampered by complying to restrictions on gatherings and events.

- The results may not be applicable to medical students in different contexts.

- A strength of the study was the conduction of the survey while the COVID-19 pandemic was evolving.

- Inviting all medical students at the university supported identifying changes in motivation with advancing study year.

an immediate increase in intensive care unit admissions and fatalities have stunned the country. ${ }^{3}$ Mid-February 2020, the alarm for an unknown presence of SARS-COV-2 in the Italian population was set-off. Here, a patient tested positive for SARS-COV-2 and admitted to intensive care in Lodi, Lombardy, Italy. During the following 24 hours, an additional 35 cases were admitted without transmission from the first case. Thus, Italy sets the scene through a case scenario for what is to come for healthcare systems across the world, with a high risk of these being pushed beyond capacities. Thus, promptly preparing health services to deal with such a scenario is crucial.

It is critical to be aware that healthcare staff is a finite resource that is likely to become depleted during a pandemic as a result of illness. ${ }^{4}$ Further, one in four doctors and final-year medical students may abandon work during a pandemic to protect their families and themselves. ${ }^{5}$ The lack of healthcare workers has earlier been described during both the influenza pandemic of 1918 and the polio epidemic in $1952 .{ }^{6} 7$ Here, medical students were key contributors to the 
pandemic emergency healthcare workforce and ensured vital care for patients. A Belgian Study conducted in 2009 suggested that more than $80 \%$ of medical students would contribute to caring for pandemic patients. ${ }^{8}$

A recruitment strategy focusing on medical students as contributors could offer a solution to a healthcare workforce depletion during the current COVID-19 pandemic. Hence, it is essential to identify what motivates medical students to join a pandemic emergency healthcare workforce. This led us to conduct a survey among all medical students at Aalborg University, Aalborg, Denmark, on what motivates them to join the pandemic emergency healthcare workforce, as the pandemic was in its early phase.

\section{METHODS}

This paper is reported according to the "Strengthening the Reporting of Observational Studies in Epidemiology" guideline. $^{9}$

\section{Study design and setting}

We conducted a cross-sectional study using a survey questionnaire distributed at one point in time. The questionnaire was distributed on 16 March 2020 to all medical students at Aalborg University through individual, institutional email addresses. Data collection closed on 23 March 2020.

\section{Participants}

We invited all medical students enrolled at Aalborg University, Aalborg, Denmark, at the time the questionnaire was distributed $(n=688)$. No exclusion criteria were applied. Admission to medical schools in Denmark relies on grades, medical education is free of charge, and it takes 6 years to become a medical doctor. At the medical school of Aalborg University, the guiding teaching principle is problem-based learning, and years $4-6$ comprise learning in a clinical environment qualifying students to work as locum physicians when having completed the fourth year. Thus, a fourth-year medical student locum physician does supervised admissions and ward rounds with the attention of qualified doctors reviewing patients and notes.

The total number of medical students at Aalborg University increases by year groups as the medical education at Aalborg University expanded from an initial 35 graduating students in 2016 to an annual admission of 179 students from 2018 onwards.

\section{Variables}

\section{Development of the research questionnaire}

The questionnaire was constructed in a four-phase process. First, an expert panel was established comprising a medical student (AWE) to ensure medical students' priorities, experience and preferences, a junior doctor (MSA) and a senior consultant with a focus on education (SA). This group performed a brainstorm on all likely relevant motivational domains that could motivate medical students to join the pandemic emergency healthcare workforce. Second, a selection of key domains that were considered to influence medical students' motivation on volunteering for the pandemic emergency healthcare workforce during the COVID-19 crisis was performed. Third, the questionnaire was constructed, and a final iteration focused on adding missed domains by two experts on education (JE and SR). Fourth, a process of method optimisation was conducted to enhance the quality of the final questionnaire (GVBS and SA).

\section{Content of the questionnaire}

The questionnaire is available in the online supplemental appendix in an English translation as well as the original version in Danish. It includes questions on both demographics and motivational factors. For demographics, we recorded gender, age, number of semesters completed and clinical experience obtained aside from clinical placements planned in the curriculum. For questions on motivational factors, we presented 11 motivational statements following an overarching question: 'To what degree are the following statements important for you to join a national emergency preparedness workforce?' (translation from Danish: 'I hvilken grad er følgende udsagn vigtige for, at du melder dig til at indgå $\mathrm{i}$ et nationalt pandemiberedskab?'). The motivational statements included revolved around the care for fellow human beings, learning opportunities, pride in contributing, being part of the doctoral fellowship, being needed, own safety, supervision, job opportunities, duty, salary and participation in a historical event. Students were asked to score each statement on a Visual Analog Scale from 0 to 100 with 0 being to a very low extent and 100 being to a very great extent. The questionnaire concluded by asking their status regarding joining the pandemic emergency healthcare workforce with reply options being: 'have joined', 'want to join', 'consider joining', 'have decided not to join' or 'undecided as to whether to join or not'.

\section{Data management}

The data were collected and managed using the Research Electronic Data Capture (REDCap) electronic data capture tools hosted at Region Nordjylland. ${ }^{10}{ }^{11}$ REDCap is a secure, web-based software platform designed to support data capture for research studies, providing (1) an intuitive interface for validated data capture; (2) audit trails for tracking data manipulation and export procedures; (3) automated export procedures for seamless data downloads to common statistical packages and (4) procedures for data integration and interoperability with external sources.

\section{Bias}

Selection bias in our available population was avoided by distributing the questionnaire to all medical students. We strived to avoid non-response bias by using neutral wording and formulations. 


\section{Statistical analysis}

In Denmark, one semester is equal to a half-year of education, and we merged semesters to report advancement in full study years completed. Age groups were constructed by 20 years and below, 21-25 years, 26-30 years and 31 years or older. Years of clinical experience were calculated, and students were grouped by below 1 year, 1-2 years, 2-3 years and more than 3 years. For the question on motivational factors, we considered a score above 60 as high and above 80 as very high.

Variables were summarised using standard descriptive statistics. If normally distributed, continuous and discrete, variables were summarised using means with SD. If non-normally distributed medians with IQR were used. Normality of distributions was checked using $Q-Q$ plots and histograms. Categorical data were displayed using proportions. Comparisons were performed using MannWhitney for comparison of two groups, Kruskal-Wallis test for comparison of several groups and the $\chi^{2}$ test for comparing proportions. A $\mathrm{p}$ value of less than 0.05 was considered statistically significant.

Missing data accounted for $0.10 \%$ of demographic data and $0.36 \%$ of motivational statements. Therefore, imputations were not performed, and observations with missing data were otherwise included in the analyses.

The sample size was determined by the number of medical students enrolled at the bachelor and master programmes in medicine at Aalborg University, Aalborg, Denmark, during the study period. The statistical software for the Social Sciences was used (IBM Corp. IBM SPSS Statistics for Windows, V.13.0. NY: IBM Corp.).

\section{Patient and public involvement}

Patient and public involvement were hampered by restrictions on unnecessary assemblies. Combined with the urgency of this study, the public and patient involvement were limited to the inclusion of a representative medical student.

Patient and public involvement were incorporated by giving AWE a distinct role during the problem-based learning process. ${ }^{12} \mathrm{AWE}$ contributed to the clarification of terms, had a separate time slot during brainstorming and making the scribe list. All views by AWE on each issue were recorded and considered. A similar emphasis was put on the student contribution put forward by AWE during the discussion of problems and possible explanations drawn on the student's knowledge and identification of areas of incomplete knowledge during the review step. ${ }^{12}$ This contributed to the selection of domains and the construction of the questionnaire. AWE added to the consideration of the burden and time required to participate in the survey. AWE is a fifth-year vmedical student representing medical students by being the head of the Danish Medical Students organisation for Anesthesiology and Traumatology, a member of Medical Students Council, a member of Aalborg University Hospital's steering committee on education of medical students to participate in the pandemic as well as a locum physician at the Department of Orthopaedic Surgery at Aalborg University Hospital. The experience along with contacts among fellow students and organisations will contribute to the dissemination of the survey results among students regionally and nationally.

\section{RESULTS}

\section{Characteristics of participants}

The participation rate was $70.6 \%$ with 486 out of 688 medical students responding to the survey invitation, and with $415(60.3 \%)$ responding within 48 hours. Table 1 lists the characteristics of the medical students participating. The sample did not differ from the available population of medical students at Aalborg University in terms of gender (male/female, $32.3 \% / 67.7 \% ; \chi^{2} 0.16, \mathrm{p}>0.1$ ), and age (median (IQR): 23 (3) years in the sample, $\mathrm{p}>0.1$ ). The median (IQR) of clinical experience was 3 (12) months. All but $35.2 \%$ had previous clinical experience. Being a substitute assistant nurse was the main non-curricular clinical occupation accounting for $35.8 \%$ of all medical students. Secondarily, being a locum physician was seen in $13.6 \%$ of all medical students and $27.5 \%$ of those in the final 3 clinical years.

\section{Motivation scores}

Four out of five stated that they had joined or wanted to join the pandemic emergency healthcare workforce, while $18.4 \%$ (89) were undecided (table 1).

Table 2 lists the scores for each statement ranked by score. In general, the scores were high or very high with 'care for fellow human beings', 'learning opportunities', and 'pride in contributing' receiving the highest scores. 'Being part of the doctoral fellowship' and 'being needed' receive a high score along with 'own safety' and 'supervision'. 'Participation in a historic event' and 'salary' did not receive high scores.

\section{Worries added by students}

Additional motivational factors mentioned by responding students were primarily related to study activities. The competition for the time used for studying, uncertainty regarding the need for reading, changing of study plans and the risk of being barred from exams due to absence from clinical placements were concerns raised. Encouragement from the university was essential to some. Also, the risk of being infected was listed as a priority. To the other end, helping future colleagues was emphasised along with the quality and kind of work they would participate in. Finally, it was stated that the questions should have been on what prevents medical students from contributing rather than on what motives them to join.

\section{Differences among students}

'Supervision' was given increasing priority with advancing study years. Scores for 'duty' rose after the early study years. 'Salary' received low scores during the first 3 years, and was higher in medical students at the 3 final clinical 
Table 1 Characteristics of medical students participating in the survey

N

\begin{tabular}{|c|c|c|c|c|c|}
\hline \multicolumn{6}{|l|}{ Age groups } \\
\hline & 21-25 years & & 71,6 & 348 & \\
\hline & $31+$ years & & 4.1 & 20 & \\
\hline & & Total & 100 & 486 & \\
\hline & Male & & 31.1 & 151 & \\
\hline & Female & & 68.5 & 332 & \\
\hline & Other & & 0.4 & 2 & \\
\hline & & Total & 100 & 485 & \\
\hline \multirow{5}{*}{ Study year } & 3. & & 21.4 & 104 & 126 \\
\hline & 4. & & 16.5 & 80 & 108 \\
\hline & 5. & & 15.0 & 73 & 83 \\
\hline & 6. & & 5.8 & 28 & 49 \\
\hline & & Total & 100 & 486 & 688 \\
\hline \multicolumn{6}{|c|}{ Clinical experience (years) ${ }^{*}$} \\
\hline & $<1$ year & & 76.0 & 369 & \\
\hline & $1-2$ years & & 12.2 & 59 & \\
\hline & $2-3$ years & & 6.0 & 29 & \\
\hline & Do not know & & 1.9 & 9 & \\
\hline & Would not join & & 1.6 & 8 & \\
\hline & Total & & 100 & 486 & \\
\hline \multicolumn{6}{|c|}{ Among decided } \\
\hline & Yes & & 98.0 & 389 & \\
\hline & No & & 2.0 & 8 & \\
\hline & & Total & 100 & 397 & \\
\hline
\end{tabular}

*Missing data; one gender; one clinical experience.

†The total number of medical students enrolled by each study year.

years. Scores for 'care for fellow humans' were higher by female students, but scores were high for students of all genders. 'Salary' was given increasing priority with clinical experience $(\mathrm{p}<0.001)$.

The eight who had replied 'decided not to participate' in the pandemic emergency healthcare workforce had markedly lower scores for 'care for fellow humans' compared with those who replied 'aimed to joined' or 'had joined' (median 77/100/100, p<0.001). The same accounted for 'being part of the doctoral fellowship' $(65 / 75 / 80, \mathrm{p}=0.005)$ and for 'pride in contributing' $(60 / 86 / 90, \mathrm{p}<0.001)$. 'Safety' scored slightly different $(97 / 75 / 75, \mathrm{p}=0.056)$. 
Table 2 Scores for joining the pandemic emergency healthcare force as stated by medical students in reply to the question (the students were not shown the domains presented in this table)

\begin{tabular}{|c|c|c|c|c|c|}
\hline Domain & Question asked & Median & $\begin{array}{l}25 ; 75 \\
\text { percentiles }\end{array}$ & Mean & $\begin{array}{l}P \text { value; gender/study } \\
\text { year }\end{array}$ \\
\hline \multirow[t]{2}{*}{ Care } & & & & 92.8 & \\
\hline & $\begin{array}{l}\text { I would like to help my } \\
\text { fellow human beings }\end{array}$ & 100 & $88 ; 100$ & & $0.001 / 0.068$ \\
\hline \multirow[t]{2}{*}{ Learn } & & & & 84.7 & \\
\hline & $\begin{array}{l}\text { I will be provided an } \\
\text { opportunity to learn } \\
\text { something }\end{array}$ & 90 & $75 ; 100$ & & $\mathrm{~ns} / \mathrm{ns}$ \\
\hline \multirow[t]{2}{*}{ Pride } & & & & 79.0 & \\
\hline & $\begin{array}{l}\text { I will take pride in } \\
\text { contributing }\end{array}$ & 83 & $66 ; 100$ & & $\mathrm{~ns} / \mathrm{ns}$ \\
\hline \multirow[t]{2}{*}{ Team } & & & & 73.3 & \\
\hline & $\begin{array}{l}\text { I become a part of the } \\
\text { doctoral fellowship }\end{array}$ & 77 & $60 ; 100$ & & $\mathrm{~ns} / \mathrm{ns}$ \\
\hline \multirow[t]{2}{*}{ Needed } & & & & 73.4 & \\
\hline & $\begin{array}{l}\text { I am informed that I am } \\
\text { needed }\end{array}$ & 75 & $60 ; 94$ & & $\mathrm{~ns} / 0.053$ \\
\hline \multirow[t]{2}{*}{ Safety } & & & & 71.7 & \\
\hline & $\begin{array}{l}\text { Precautions have been } \\
\text { taken to prevent me } \\
\text { from getting infected } \\
\text { during work }\end{array}$ & 75 & $50 ; 99$ & & $0.024 / 0.085$ \\
\hline \multirow[t]{2}{*}{ Supervision } & & & & 72.5 & \\
\hline & $\begin{array}{l}\text { I will receive supervision } \\
\text { in my work }\end{array}$ & 75 & $55 ; 93$ & & $0.014 /<0.001$ \\
\hline \multirow[t]{2}{*}{ Job } & & & & 69.4 & \\
\hline & $\begin{array}{l}\text { I develop my } \\
\text { professional job profile }\end{array}$ & 73 & $51 ; 93$ & & $0.030 / 0.003$ \\
\hline \multirow[t]{2}{*}{ Duty } & & & & 60.1 & \\
\hline & It is expected from me & 66 & $47 ; 80$ & & $\mathrm{~ns} / 0.001$ \\
\hline \multirow[t]{2}{*}{ Salary } & & & & 60.9 & \\
\hline & I get paid for my work & 62 & $50 ; 84$ & & $\mathrm{~ns} /<0.001$ \\
\hline \multirow[t]{2}{*}{ History } & & & & 50.9 & \\
\hline & $\begin{array}{l}\text { I become part of a } \\
\text { historic event }\end{array}$ & 50 & $21 ; 76$ & & $0.060 / \mathrm{ns}$ \\
\hline
\end{tabular}

ns: $p>0.1$ in Mann-Whitney and Kruskal-Wallis test for gender and study year, respectively. Fifteen responders had missing data comprising $0.3 \%$ of all data. Imputations were omitted.

To what degree are the following statements important for you to join a national emergency preparedness workforce for a pandemic?

Scores were on a scale from 0 to 100.

\section{DISCUSSION}

\section{Key results}

The motivation for joining a pandemic emergency healthcare workforce was reported by medical students to be an urge to help fellow human beings, a learning opportunity and taking pride in contributing. In addition, motivational factors given priority were joining the doctoral fellowship, their help being needed, their safety and guidance at work. The majority of medical students were willing to participate in the pandemic emergency healthcare workforce, but they had concerns that should be and can be addressed when acknowledged. Hospitals and senior colleagues can accommodate the request for supervision in the clinical work using available tools and thereby support unique learning opportunities for medical students. ${ }^{13}$ Such collaborative efforts support medical students teaming up with the medical fellowship to strengthen the push for participation and learning further. ${ }^{14}$ Also, this can be a benefit to the students' selfsatisfaction and appreciation of their efforts. 
Importantly, medical students responded that their safety while working was a priority. Hospitals should address this concern during training sessions and theoretical pre-qualification before students start clinical practice. Senior colleagues should further address and support safety during clinical work. The students' response uncovered a limited emphasis on salary and academic resume. Still, these factors were of some interest and may be discussed during recruitment.

Factors linked to study activity should be addressed. The university should settle uncertainty concerning study plans and exams to provide clear guidance for students. Finally, students listed that encouragement by the university to participate in a pandemic emergency healthcare workforce could be an incentive.

\section{Strengths and Limitations}

A strength of this survey was the timing. The COVID-19 pandemic was announced at the time of sending out survey invitation, and death rates were high in China and rapidly rising in Southern Europe while the link was open. This emphasised the severity of the situation and may have encouraged medical students to consider whether to participate in the pandemic emergency workforce. Also, this may have supported the high response rate of $71 \%$. Age, gender and distribution between study years were comparable between responders and non-responders. It may be speculated that non-responders were undecided students. The scores of $18.4 \%$ of responders undecided on whether to join the pandemic emergency healthcare workforce were just under median scores. Adding such scores is unlikely to alter the conclusions.

A limitation of the study is that the constructed questionnaire primarily addresses positive motivational points as to joining the pandemic healthcare workforce and not what is impeding to the students. This could have further helped to guide clinicians and administrators contributing to a further elaborate list of items and priorities to take into account. A note must be taken that the survey was performed in Denmark, which has tax-funded healthcare and free education. This could influence the motivation of the students. The limitations regarding the involvement of the patient and the public may have hindered uncovering further relevant aspects and resulted in a limited representation of relevant groups.

\section{Interpretation}

An earlier study reported that more than $80 \%$ of medical students in the USA would volunteer to participate in the healthcare workforce during a pandemic. ${ }^{4}$ Our numbers were similar for a tax-funded healthcare system in Europe, and they are in line with a Belgian Study reporting that $80 \%$ of final year medical students would volunteer during a pandemic. ${ }^{8}$ Also, a concern for educational interruptions with an ongoing pandemic crisis was similar between our medical students in Europe and a group in North America. ${ }^{15}$ The motivation of healthcare workers in general during a pandemic parallel some of our findings among medical students, including safety, being part of a team and feeling useful. ${ }^{1617}$

\section{Generalisability}

The generalisability is affected in a few ways. First, the survey was conducted at a university using problembased learning and a spiral curriculum with the students embedded in the clinical environment for the final 3 years. ${ }^{18}$ Second, education being for free may also influence motivation. However, medical students responded similarly in two domains to those in North America, suggesting similar responses despite these differences.

\section{Clinical implications}

The most obvious implication is that medical students provide a resource eager to contribute to patient treatment and care during a pandemic emergency if few essential needs are met as detailed in this report and that this can easily be accommodated. In the case of an evolving pandemic, occurrence of local outbreaks and secondary waves of infections, access to this resource will become essential for decision-makers and policy-makers, both for the sake of patients and healthcare personal.

\section{Future research}

Future studies could evaluate if priorities changed with the crises at a distance and if priorities vary between medical students at universities with different curricula and pedagogical approaches to learning. Also, they should explore factors impeding medical student response and their concern for protection. Medical students may be motivated to contribute to the healthcare workforce if work during a pandemic is relevant to learning objectives. Studies to explore such opportunities are warranted.

\section{CONCLUSION}

The present study provides a list of items and priorities to inspire and guide clinicians and administrators at both hospitals and universities to support recruiting medical students for a pandemic emergency healthcare workforce. Importantly, students emphasised safety for themselves. Hands-on recommendations include focussing on learning opportunity, supervision, acceptance of educational interruptions by, and support from, university.

Contributors Conceptualisation: MSA, SR, JE, AWE and SA. Formal analysis: MSA and SA. Methodology: MSA, AWE, SA, SR, JE and GVBS. Project administration: MSA and SA. Resources: SA, GVBS and JE. Software: GVBS. Supervision: SA and GVBS. Validation: JE. Visualisation: MSA. Writing —original draft preparation: MSA. Writing — review and editing: MSA, SA, GVBS, AWE, SR and JE. The corresponding author attests that all listed authors meet authorship criteria and that no others meeting the criteria have been omitted. MSA is the guarantor of the study.

Funding The authors have not declared a specific grant for this research from any funding agency in the public, commercial or not-for-profit sectors.

\section{Competing interests None declared.}

Patient and public involvement Patients and/or the public were involved in the design, or conduct, or reporting, or dissemination plans of this research. Refer to the Methods section for further details.

Patient consent for publication Not required. 
Ethics approval Written informed consent was obtained from all students by agreeing to answer the questionnaire. Due to the study being a survey, ethical approval was not required according to the Danish Act on the Scientific Ethical Committee System (Act no. 593, section 14, subsection 2). Approval was obtained from the Danish Data Protection Agency (record number 2020-030).

Provenance and peer review Not commissioned; externally peer reviewed.

Data availability statement № data are available. The questionnaire will be shared in the appendix both in the original (Danish) and in a translation to English. Extra data are available by emailing the corresponding author while individual participant data cannot be shared for the reason of confidentiality.

Open access This is an open access article distributed in accordance with the Creative Commons Attribution Non Commercial (CC BY-NC 4.0) license, which permits others to distribute, remix, adapt, build upon this work non-commercially, and license their derivative works on different terms, provided the original work is properly cited, appropriate credit is given, any changes made indicated, and the use is non-commercial. See: http://creativecommons.org/licenses/by-nc/4.0/.

\section{ORCID iDs}

Mike Sæderup Astorp http://orcid.org/0000-0003-4062-6027

Stig Andersen http://orcid.org/0000-0003-3632-5213

\section{REFERENCES}

1 Zhou F, Yu T, Du R, et al. Clinical course and risk factors for mortality of adult inpatients with COVID-19 in Wuhan, China: a retrospective cohort study. Lancet 2020;395:1054-62.

2 Kinross P, Suetens C, Gomes Dias J, et al. Rapidly increasing cumulative incidence of coronavirus disease (COVID-19) in the European Union/European economic area and the United Kingdom, 1 January to 15 March 2020. Euro Surveill 2020;25. doi:10.2807/15607917.ES.2020.25.11.2000285. [Epub ahead of print: 16 Mar 2020].

3 Grasselli G, Pesenti A, Cecconi M. Critical care utilization for the COVID-19 outbreak in Lombardy, Italy. JAMA 2020;323:1545.
4 Herman B, Rosychuk RJ, Bailey T, et al. Medical students and pandemic influenza. Emerg Infect Dis 2007;13:1781-3.

5 Ehrenstein BP, Hanses F, Salzberger B. Influenza pandemic and professional duty: family or patients first? A survey of hospital employees. BMC Public Health 2006;6:311.

6 Starr I. Influenza in 1918: recollections of the epidemic in Philadelphia. 1976. Ann Intern Med 2006;145:138.

7 Astrup P, Gotzche H, Neukirch F. Laboratory investigations during treatment of patients with poliomyelitis and respiratory paralysis. $\mathrm{Br}$ Med J 1954:1:780-6.

8 Mortelmans LJM, De Cauwer HG, Van Dyck E, et al. Are Belgian senior medical students ready to deliver basic medical care in case of a H5N1 pandemic? Prehosp Disaster Med 2009;24:438-42.

9 Vandenbroucke JP, von Elm E, Altman DG, et al. Strengthening the reporting of observational studies in epidemiology (STROBE): explanation and elaboration. PLoS Med 2007;4:e297-1654.

10 Harris PA, Taylor R, Minor BL, et al. The REDCap Consortium: building an international community of software platform partners. $J$ Biomed Inform 2019;95:103208.

11 Harris PA, Taylor R, Thielke R, et al. Research electronic data capture (REDCap)--a metadata-driven methodology and workflow process for providing translational research informatics support. J Biomed Inform 2009;42:377-81.

12 Wood DF. Problem based learning What is problem based learning ? Bmi 2003;326:328-30.

13 Spencer J. Abc of learning and teaching in medicine: learning and teaching in the clinical environment. BMJ 2003;326:591-4.

14 Dornan T, Medical M. Supporting medical students ' workplace learning. Clin Teach 2009;6:167-71.

15 Clark J. Fear of SARS thwarts medical education in Toronto. BMJ 2003;326:784c-784.

16 Anantham D, McHugh W, O'Neill S, et al. Clinical review: influenza pandemic - physicians and their obligations. Crit Care 2008;12:217-6.

17 Ives J, Greenfield S, Parry JM, et al. Healthcare workers' attitudes to working during pandemic influenza: a qualitative study. BMC Public Health 2009;9:56.

18 Andersen S, Stentoft D, Emmersen J, et al. Contention over undergraduate medical curriculum content. Int J Med Educ 2019;10:230-1. 